\title{
Comunicación diádica temprana: microanálisis de ocho casos
}

\section{Early Dyadic Communication: Microanalysis of Eight Cases}

\author{
Jorge Rafael Sanabria-León ${ }^{1}$ \\ ${ }^{1}$ Escuela de Psicología, Universidad de Costa Rica, Costa Rica
}

Resumen. Objetivo. La investigación caracteriza estilos de interacción mamá - bebé con el propósito de identificar la construcción del vínculo diádico. Se enfatizan las Formas de Interacción como concepto central para la incorporación del sujeto a la comunicación y luego al lenguaje. Método. Registros de interacciones naturales de ocho díadas a las seis semanas, seis meses y un año de vida infantil, identifican la constitución progresiva del sistema de comunicación diádico. Resultados. La elucidación de signos corporales y el surgimiento de la regulación emocional a las seis semanas, el juego con escenas sociales a los seis meses y la instauración del campo semántico diádico al año son rasgos destacados que se concatenan entre sí durante el proceso. La triangulación con el entorno social es una constante en la interacción.

Palabras clave. Comunicación, lenguaje, socialización temprana, vínculo diádico.

Abstract. Objective. This paper characterizes mother-baby interaction styles for the purpose of identifying dyadic bonding throughout the first year of life. The Forms of Interaction are emphasized as a central concept for the incorporation of the subject into communication and then to language. Method. Records of natural interactions from eight dyads to six weeks, six months and one year of age identify the progressive constitution of the dyadic communication system. Results. The elucidation of body signs and the emergence of emotional regulation at six weeks, the interplay with social scenes at six months, and the establishment of the dyadic semantic field at one year are salient features that intertwine during the process. Triangulation with the social environment is a constant within the interaction.

Keywords. Communication, language, early socialization, dyadic bond.

${ }^{1}$ Jorge Rafael Sanabria-León. Universidad de Costa Rica, Sede Rodrigo Facio, Escuela de Psicología. Dirección postal: 2060 San José, Costa Rica. E-mail: jorge.sanabria@ucr.ac.cr

\section{(®) $(\Theta \Theta$}




\section{Introducción}

La capacidad materna para transmitir el lenguaje, y la infantil de adquirirlo, constituyen un proceso de mutua estimulación. La capacidad neurofisiológica infantil se potencia con la mediación cultural diádica. Comunicación y lenguaje se propician desde las prácticas culturales de crianza. Según Edwards y Liu (2002), y Thomson (2006), la interacción diádica se sitúa en el microsistema, las prácticas de crianza en el mesosistema y la mediación cultural en el exosistema.

El modelo teórico contempla Formas de Interacción (FI) provenientes de la Fase de Advenimiento del Lenguaje (Lorenzer, 2002), como proceso simbólico y diádico, desde interacciones no verbales, con raigambre en la sensorialidad corporal. Tomasello (2009) aporta una visión comprensiva de la comunicación diádica preverbal, así como de la cooperación sustentada en la sincronización de mirada y señalamiento (pointing). Asimismo, Karmiloff y Karmiloff-Smith (2001) destacan el habla infantilizada (baby talk), así como uso y función de la prosodia.

Este sistema de comunicación parte del sustrato neurofisiológico y se expresa en precursores del habla (protosign y protospeech, Arbib, Gasser, \& Barrés, 2014), así como en la participación de neuronas espejos en gestos y evolución del lenguaje (Coudé et al., 2016), que permiten al/ la bebé reconocer indicios del comportamiento materno y mostrar estados nacientes de su percepción general del entorno y del sí mismo. Este proceso se articula en la individualidad como regulación emocional (DiCorcia, Snidman, Sravish, \& Tronick, 2016).

Progresivamente, el sistema de comunicación faculta al sujeto a construir cogniciones incipientes (De Houwer \& Hermans, 2010), sobre la experiencia interactiva y a asociarles emociones. Ambas transportan consigo contenidos simbólicos culturales. Una noción cognitiva implica una representación de la acción particular en el entorno y las emociones asociadas enlazan el significado subjetivo. Estos contenidos simbólicos conforman estilos de crianza maternos, particularmente en el andamiaje (scaffolding) lúdico (Marjanovič-Umek \& Fekonja-Peklaj, 2017), visibles en las prácticas interactivas maternas. El sistema de comunicación - cooperación para la comprensión de la interacción en gestación, visualiza al/la bebé como un individuo competente desde el desarrollo temprano.

Este modelo presenta al sujeto infantil competente, dotado de disponibilidad epigenética para la comunicación, en medio del andamiaje diádico que consolida formas de interacción; cuyo contenido refleja estilos maternos de crianza que orientan al sujeto hacia la adquisición de significados culturales. El resultado del proceso habrá de transformarse en germen de contenidos de cogniciones sociales y de modelos relacionales socioafectivos. Por tanto, es posible hipotetizar que la observación naturalista de estilos espontáneos de interacción entre madre y bebé muestran estrategias en acción para lograr metas de socialización específicas. ¿Cómo recibe la mamá el desafío comunicativo del bebé; y cómo procesa su bebé la oferta de interacción materna, para que se geste mutuamente un vínculo diádico con rasgos que lo distinguen como un modelo esencial de relacionarse socialmente?, es la pregunta de esta investigación. Se conjeturó, según el enfoque teórico, que la comunicación precede al lenguaje articulado infantil, pero también que es condición sine qua non para adquirirlo en virtud de su mediación simbólica. 


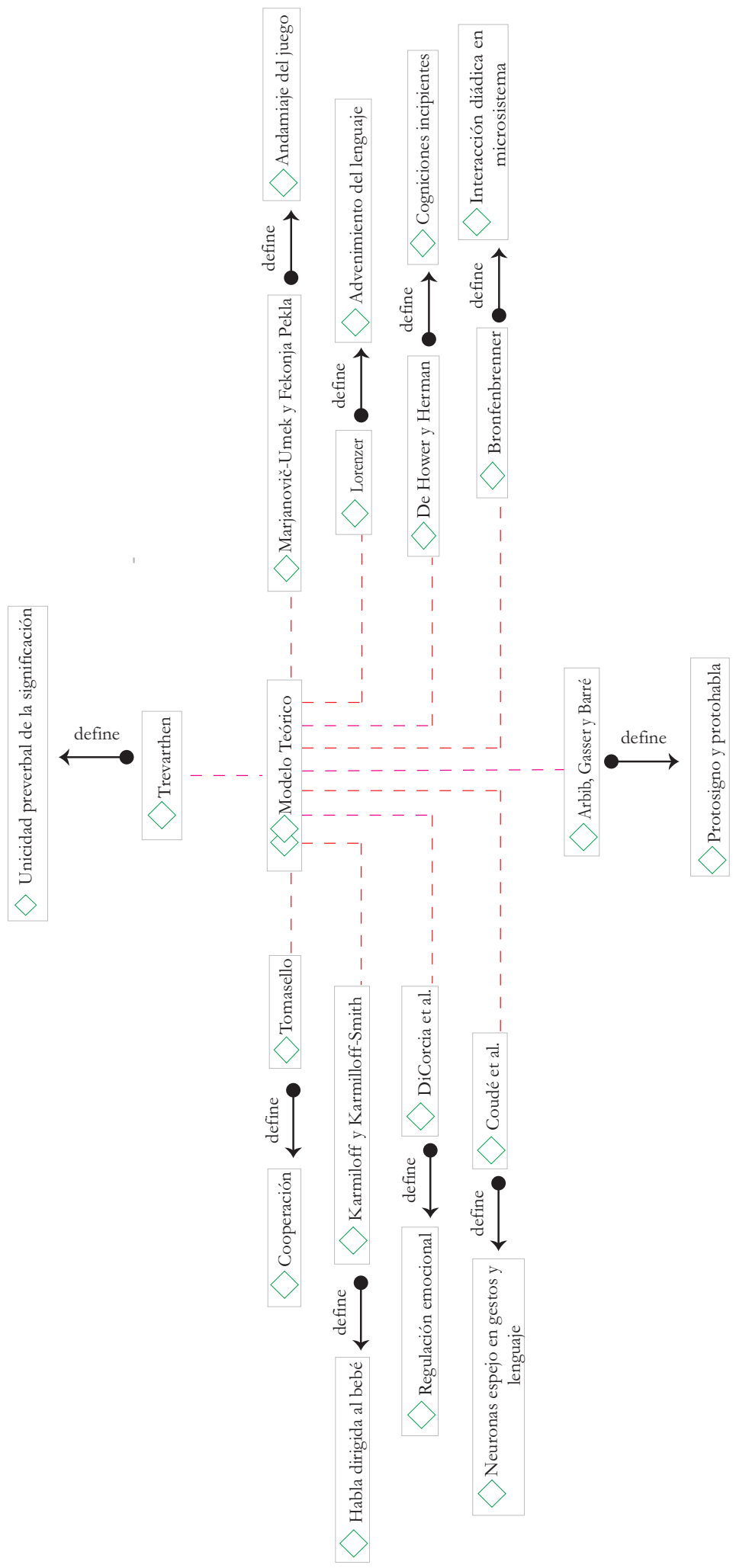

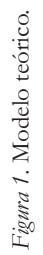

Actualidades en Psicología, 34(128), 2020, 69-101 
Este enfoque se apoya también en el concepto de "unicidad preverbal de la significación humana" (Trevarthen, 2015a, 2015b). El cual atribuye a la musicalidad satisfacer la necesidad infantil del dramatismo en juegos infantiles con acompañantes, claves dinámicas que requieren integrar diferentes modos de pensamiento fundados en relaciones empáticas para generar un sentido del mundo, formas que aparecen antes de conciencia y lenguaje; cuyas modulaciones contribuyen a comunicar y aprehender la complementariedad diádica, que coloca a la comunicación sobre la base de sentimientos cooperativos y sincrónicos (Kokkinakia, Vasdekis, Koufakia, \& Trevarthen, 2017).

Los estudios latinoamericanos sobre infancia y socialización o sobre socialización y lenguaje atienden a: la funcionalidad del lenguaje y su papel en el aprendizaje (Morales-González, Lázaro-García, Solovieva, \& Quintanar-Rojas, 2014; Ospina-Ospina \& Gallego-Henao, 2014), o enfatizan la dimensión sociocultural articulada en prácticas de crianza inscritas en el mesosistema (Peña-Ramos, Vera-Noriega, \& Santiz-López, 2018; Varela-Londoño, Chinchilla-Salcedo, \& Murad-Gutiérrez, 2015; Vargas et al., 2016; Vergara-Hernández, 2017; Andrés-Viloria \& Fernández-González, 2016). En otros casos, se considera la dimensión socioemocional (Calderón, 2017) y hasta su relación con la cognición (Baquero \& Segovia, 2018) y cómo se proyecta en la compresión del mundo social (BermúdezJaimes \& Escobar, 2014).

Woldarsky, Urzú, Farkas y Vallotton (2019) insisten en que las diferencias culturales se miden como una función de la sensibilidad materna resultante en la lectura de necesidades infantiles y respuestas acordes, o no, que contribuirán a establecer la distinción entre metas de socialización. Tales como independencia, exploración y autosuficiencia; en oposición con autorregulación y satisfacción de deseos infantiles, conducentes a perfiles contrastantes de socialización.

El modelo de esta investigación intenta una visión multidimensional de la caracterización diádica emergente en el vínculo primario durante la infancia temprana, no solo como un asunto de proclividad a la mentalización materna (mind-mindedness, cf. Mcmahon, Camberis, Berry, \& Gibson, 2016), o estrictamente de apego (cf. Pickard, Townsend, Caputi, \& Grenyer, 2017), sino más de un entonamiento afectivo (affect attunement, cf. Bordoni, 2018), basado en un placer compartido (shared pleasure, cf. Puura et al., 2019) que visualiza a la mamá y a la diada en sí como agentes culturales (Leithäuser, 2012). Así, las nociones de crianza provenientes del exosistema permean modelos específicos en el mesosistema que son detectables en modalidades diádicas en el microsistema; e inauguran la ontogénesis de una perspectiva de mundo (Fajardo-Santamaría, 2018). Por medio de una representación escénica (enactments, Morgenroth, 2010) que llevará a las madres a actuar como agentes relacionales capaces de transmitir planes culturales para que la subjetividad infantil pueda consolidarse en términos semióticos (Trevarthen, 2015a).

\section{Método}

Este estudio longitudinal registró en video interacciones diádicas cotidianas de treinta minutos en tres momentos durante el primer año de vida infantil: seis semanas, seis meses y un año, atendiendo principios de Green y Hogan (2005), realizados entre 2009 y 2011, en casas. Estuvieron presentes solamente las díadas y la asistente que filmó simultáneamente con cámaras opuestas, cara a cara. 


\section{Participantes}

Se analizan ocho díadas, cinco niños y tres niñas, de mamás primerizas ( $M=22.5$ años), del Área Metropolitana de San José, pertenecientes, según lugar de residencia, ingreso promedio e ingreso per capita del hogar, al "estrato uno", correspondiente a ingreso mayor a un salario mínimo y hasta dos salarios mínimos (MIVAH, 2018). Conforman familias biparentales, nucleares (no conviven otros familiares). Dos tienen estudios universitarios y, las demás, secundaria completa. De familias con bebés a término, edad gestacional promedio y sin complicaciones durante embarazo o parto. No se reportaron enfermedades graves ni trastornos del desarrollo. Las mamás fueron contactadas en servicios públicos de salud por muestreo no probabilístico en cadena. El proyecto siguió criterios del Comité Ético-Científico de la Universidad de Costa Rica. El cual exige presentar y firmar, previo a recolectar datos, un consentimiento informado sobre objetivos, alcances y procedimientos de la investigación, la participación voluntaria tanto como la retirada sin implicaciones, y la ausencia de riesgos para las participantes.

\section{Procedimiento}

El microanálisis etnográfico o microetnografía de interacción social (Riggins, 2011) estudia unidades mínimas de interacción, situaciones puntuales con "vida propia", influidas por contextos societales y constituidas en pequeños escenarios sociales delimitados; pues factores objetivos no determinan totalmente formas particulares en que se interactúa en situaciones concretas. Riggins (2011) indaga interacciones "naturales", acciones en tiempo real, de cerca y repetidamente, con énfasis en utilización del lenguaje y otras formas de comunicación, durante la construcción de situaciones cotidianas.

Beebe (2017) trabaja el proceso de comunicación mamá - infante, momento a momento, cara a cara, para caracterizar el sistema de comunicación diádica emergente. Este "microanálisis de la interacción" identifica eventos "instante por instante", que escaparían al "ojo desnudo". Su descripción, inicialmente topológica, va reformulándose en sistemas de complejidad creciente sobre la dinámica de interacción específica.

$\mathrm{Al}$ analizar elementos de la comunicación cara a cara, en el comportamiento no verbal y la pragmática comunicativa en su contexto. Bull (2002) parte de detalles finos de la interacción durante la comunicación interpersonal. Esta perspectiva del análisis de la conversación es abordada para el tema del origen diádico de la comunicación y el lenguaje, por Gardner y Forrester (2010).

Coincidente es el registro fotográfico o fílmico de interacciones en contextos naturales (validez ecológica); y la decantación de secuencias interactivas por medio de identificar, describir y reseñar, sistemáticamente, la comunicación diádica.

La Etnografía de la Comunicación (Seville-Troike, 2003; Johnstone \& Marcellino, 2010), indaga sobre lo que un hablante común necesita saber para comunicarse apropiadamente en una comunidad lingüística, y qué necesita aprender para su competencia comunicativa. Estudia sistemas de eventos comunicativos que promueven el significado social convenido; las formas emergentes de comunicación son de particular interés. 
Barbosa, Beeghly, Moreira, Tronick y Fuertes (2018) plantean el intercambio cara a cara como el grado de coordinación diádica para establecer una relación y comprensión mutua, base de habilidades sociales y formas culturales de comunicación. Enfatizan emparejamiento y sincronía en la interacción que permiten a la díada movimientos conjuntos (intersubjetividad) longitudinalmente, sin importar el contenido. La oscilación entre descoordinación (estado más frecuente) y coordinación (reparación) favorece el ajuste y estabilización del sistema.

Antes del primer año de vida, Peck (2003) muestra cómo el/la bebe registra la sutileza de expresiones faciales, ritmos quinestésicos y múltiples combinaciones de expresividad materna; y responde en concordancia, consolidando sus expectativas sobre la acción en curso.

Diferentes mecanismos destacados por Lang et al. (2014) durante el primer año de vida, reflejan cómo bebés entienden la conducta humana con una direccionalidad hacia metas en el mundo, que les permite atribuir intencionalidad y propósito a agentes sociales identificados, integrando contingencias espacio - temporales.

De Barbaro, Chiba y Deák (2011) destacan la mirada como función y proceso asociado a comportamientos de codificación de información y mediación de la atención, que le permite al/la bebé auto-regular su vigilancia a eventos del entorno, durante el transcurso del primer año de vida.

La mutua sensibilidad diádica para percibir señales, corregir la elucidación, y reaccionar apropiadamente son establecidos por Keller (2018) como estabilizadores de la relación. Willits, Saffran y Lany (2017) coinciden en la incipiente capacidad infantil de organizar el mundo en categorías léxicas, por medio de claves fonológicas y distribucionales, que conforman su competencia lingüística gracias a la generalización de propiedades semánticas.

El presente microanálisis etnográfico de la interacción comunicativa a lo largo del primer año de vida utiliza la Teoría Fundamentada (Charmaz, 2014) para instrumentalizar registro, ordenamiento, codificación y sistematización. Este abordaje inductivo faculta validez ecológica al reconocer características esenciales del ecosistema que habitualmente rodea la interacción diádica. No se trata tanto de verificar categorías teóricas, como de advertir rasgos distintivos en la socialización (Wachs, 2015).

\section{Estrategias de recolección y análisis de datos}

Se grabó con dos cámaras simultáneas, una centrada en la cara de la mamá y la otra en la de su bebé; las cuales fueron sincronizadas con editor de videos para analizarse en el programa Atlas Ti.7, que identifica cronológica y secuencialmente la coordinación/descoordinación diádica. La consigna a las mamás fue realizar actividades habituales con sus bebés. Se desecharon los primeros minutos de la grabación (instauración y despliegue de la deseabilidad social) y se codificó hasta cinco minutos antes del final (estereotipia o agotamiento).

Se conformó un Manual de Codificación para describir las interacciones con base en una transcripción pormenorizada de cada secuencia de acciones, comportamientos y verbalizaciones que realizó cada díada. 
La Tabla 1 muestra el ejemplo más relevante de la Codificación Selectiva de bebé en el título, la Axial en el de la fila superior respectiva y la Abierta en las columnas respectivas. La Tabla 2 muestra la coincidente para mamá.

En Anexos se muestran tablas ejemplificadoras de codificación para seis meses y el año.

Se codificó cada video sincronizado, mamá y bebé, segundo a segundo, centrándose en la interacción cara a cara, aspectos verbales como no verbales, hasta la saturación; para identificar no solo eventos aislados, sino secuencias (sistemas). Se realizaron dos rondas de codificación por cada díada en cada momento del desarrollo, primero con atención en mamá y luego en su bebé, en registros separados e independientes, con cotejo simultáneo a posteriori gracias al registro cronológico de los videos en el programa Atlas Ti. La "saturación" consiste en la "comparación constante" de los materiales entre sí, hasta que los códigos resulten redundantes o no aparezcan nuevas dimensiones que agreguen elementos comprensivos. Este procedimiento procura la "densidad" de las categorías analíticas.

Fiabilidady validez.

Cada Codificación Abierta recoge una secuencia de comportamientos de mamás o bebés $\mathrm{de} \approx 10$ segundos, para reconocer, detallar y sistematizar el repertorio de comportamientos diádicos en cada momento.

La Codificación Axial sintetiza caracterizaciones diádicas en descriptores que muestran su relación con modalidades diádicas. Las iniciativas o complementos de mamás y bebés se agrupan en propiedades que conceptúan la dinámica interactiva. En las FI, tanto mamás como bebés toman la iniciativa o reaccionan en consonancia a la propuesta interactiva de su contraparte. Es un ciclo diádico dinámico en espiral de FI, dimensión empírica, en cuanto a acciones específicas diádicas, y la simbólica, sobre su significación social.

La Codificación Selectiva integra categorías coincidentes de la Axial entre díadas, en diferentes combinaciones y modelos consolidados, tanto de invitación a interactuar como

Tabla 1

Ejemplo de codificación bebé Orientación en reacciones corporales. Seis semanas

$$
\text { Mantenimiento de sincronización de mirada asociado al uso del habla infantilizada }
$$

Sincronización fugaz de mirada con mamá ante Voltea mirada fugazmente hacia estímulos búsqueda de ella de sincronización. visuales o auditivos del entorno.

Sigue con mirada objetos de estimulación Ante estimulación auditiva de mamá, mantiene visual. sincronización de mirada con la de ella.

Responde con estiramiento de miembros y Actitud relajada y adormilada ante estimulación cuerpo ante estimulación de mamá (verbal y quinestésica o en contacto con la piel; abre y quinestésica). cierra ojos esporádicamente (eventualmente fija mirada en la de mamá).

Retoma el estado de equilibrio en respuestas a Chupetea dedo en coincidencia con adecuaciones del patrón de estímulo de mamá. estimulación de mamá. 
Tabla 2

Ejemplo codificación mamá - Aspectos atribuidos al/ la bebé/ Orientación en reacciones corporales (seis semanas)

Adecuación de interacción a cambio en patrón de expresividad o de vocalización de bebé

Interpreta verbalizando estado de ánimo Ante pequeños cambios en estado de ánimo o fisiológicos del/la bebé ("¿Hambre?", del/la bebé (molestia, inquietud, hambre), “¿Cólico?”, “¿Sueño?”), en breves secuencias adecúa prosodia, expresividad facial y verbal dialógicas (reformulando pregunta de diversas para satisfacerle su necesidad formas)

Reiteración de interacción ante reacción (gesticulaciones/vocalizaciones) de bebé

Cuando bebé cambia de estado de ánimo (se Cuando bebé se tranquiliza luego de llanto y tranquiliza), registra, le describe y verbaliza el como resultado de estimulación, le cambia la cambio (“iYa estás tranquilito!") postura y vuelve a un estilo de estimulación previo

Sincronización inicial de reacción de mamá con estado exaltado de ánimo de bebé, con transición inmediata del modelaje materno hacia un estado de serenidad

Para interpretar estado de ánimo del/la bebé, Utiliza reacciones espontáneas, como recurre a secuencias de diferentes tonos de exclamaciones, agitar brazos o leves quejidos voz (prosodia) y diversos gestos faciales (v.g. por cólico) para interpretar estado físico o (empatía, preocupación), incluyendo sonrisas emocional (“¿Te duele la pancita?") y recurre a alternadas estimulación verbal (con modulación prosódica) y física para reconfortar

Cambio postural de bebé y adecuación de interacción ante molestia sostenida de bebé, con verbalización del efecto sobre bebé

Ante llanto espontáneo, reacciona con Ante molestia sostenida de bebé, recurre estimulación quinestésica (incluido cambiarle al cambio de postura (v.g. alzarlo) para de postura), arrullos y palabras en tono suave reconfortarlo, mientras verbaliza el cambio para tranquilizarlo

Cambio en interacción física (incluyendo contacto físico), quinestésica y verbal ante molestia (suspensión o variación de estas formas)

Reconforta verbalmente o con exclamaciones Por molestia ante la carga o estilo de estimulación (“¡Ah, ah, ah!”) verbal y quinestésica, varía patrón de estimulación (v.g. de canto a diálogo, suspensión de la estimulación quinestésica)

de identificación de la invitación a interactuar de la contraparte. Para integrarlas, se verificó la secuencialidad, familiaridad o complementariedad de estructuras decantadas durante la Codificación Axial. Cada Codificación Selectiva tiene un componente central como meta probable del desarrollo, alrededor del cual se nuclean estrategias para la acción con el mismo principio aglutinante. La codificación fue validada en cursos de Psicología de la UCR.

Diferentes secuencias de episodios que componen las interacciones muestran variedad y complementariedad diádicas y derivaron en categorías comunes sobre rasgos sustantivos. 


\section{Resultados}

Las figuras concatenan las categorías selectivas que visualizan caracterizaciones relevantes de la interacción diádica. El análisis subsiguiente describe, explica y dinamiza estas figuras en función de cómo sus contenidos apuntan a metas de socialización basadas en rasgos comunicativos diádicos.

Seis semanas: codificación selectiva de mamá y bebé

Como se aprecia en la Figura 2, las mamás y sus bebés se dirigieron a consolidar lo que grosso modo ha dado en llamarse la mentalización materna (mind-mindedness, cf. Mcmahon et al., 2016) o, con mayor precisión, una disponibilidad emocional individual y un entonamiento con las necesidades y metas de sus bebés (affect attunement, cf. Bordoni, 2018), para lograr que sus bebés adquieran la significación desde sus referentes corporales y sensoriales (Trevarthen, 2015a, 2015b).

Vocalización o denominación no se asociaron de inmediato con génesis de significado, sino con utilidad de la función articulatoria y práctica dialógica esencial (elementos básicos de comunicación y, posteriormente, de lenguaje). Acciones no verbales, como la proposición de acciones, reflejaron una retroalimentación mutua y el significado específico que progresivamente adquieren actividades comunes.

Las mamás acompañaron con la voz acciones que compartieron con sus bebés. Ellas no solo propusieron, ni sus iniciativas emergieron solamente de sus propias sensaciones, sino que se orientaron por estímulos provenientes de rasgos diversos en reacciones infantiles. Adecuaron su estimulación al expresarla con matices tonales para detonar pequeños cambios en la pauta imperante.

Las mamás no solo reanudaban su estilo frente al comportamiento infantil al proveer estímulos sensoriales, sino que elucidaban el estado anímico de sus bebés, incluso procurando la posición corporal correspondiente. La sincronización se adecuaba a la variabilidad conductual infantil, concomitante a la estabilidad en el intercambio. Procedieron así, independientemente de constatar al instante el efecto en sus bebés o de la capacidad infantil inmediata para absorber y procesar por completo la información entrante.

Las mamás estimularon como si cada acción propia tuviera un efecto determinado y verificable en sus bebés, para identificar la fuente de la inducción, ya fuera en el entorno de la interacción (incluyéndose ella) o desde el interior (o perspectiva interna) de sus bebés. Al presumir la perspectiva interna infantil, presuponían un conjunto de capacidades en desarrollo a las cuales es posible apelar, por separado o combinadamente.

Cuando presentaron el contexto, las mamás vocalizaron y verbalizaron, denominan sucesos y así los dotaron de significado. No solo introdujeron en el manejo práctico de las normas del lenguaje, incluyendo la exposición al vocabulario, sino en la otorgación de significado a acciones y eventos que configuraban.

Cuando las mamás estimularon algún sentido de sus bebés o tomaron como referente su cuerpo, en su funcionalidad o ubicación, se colocaban en la perspectiva interna de sus bebés y anticipaban sus sensaciones y experiencias, así como su impacto en secuenciación 


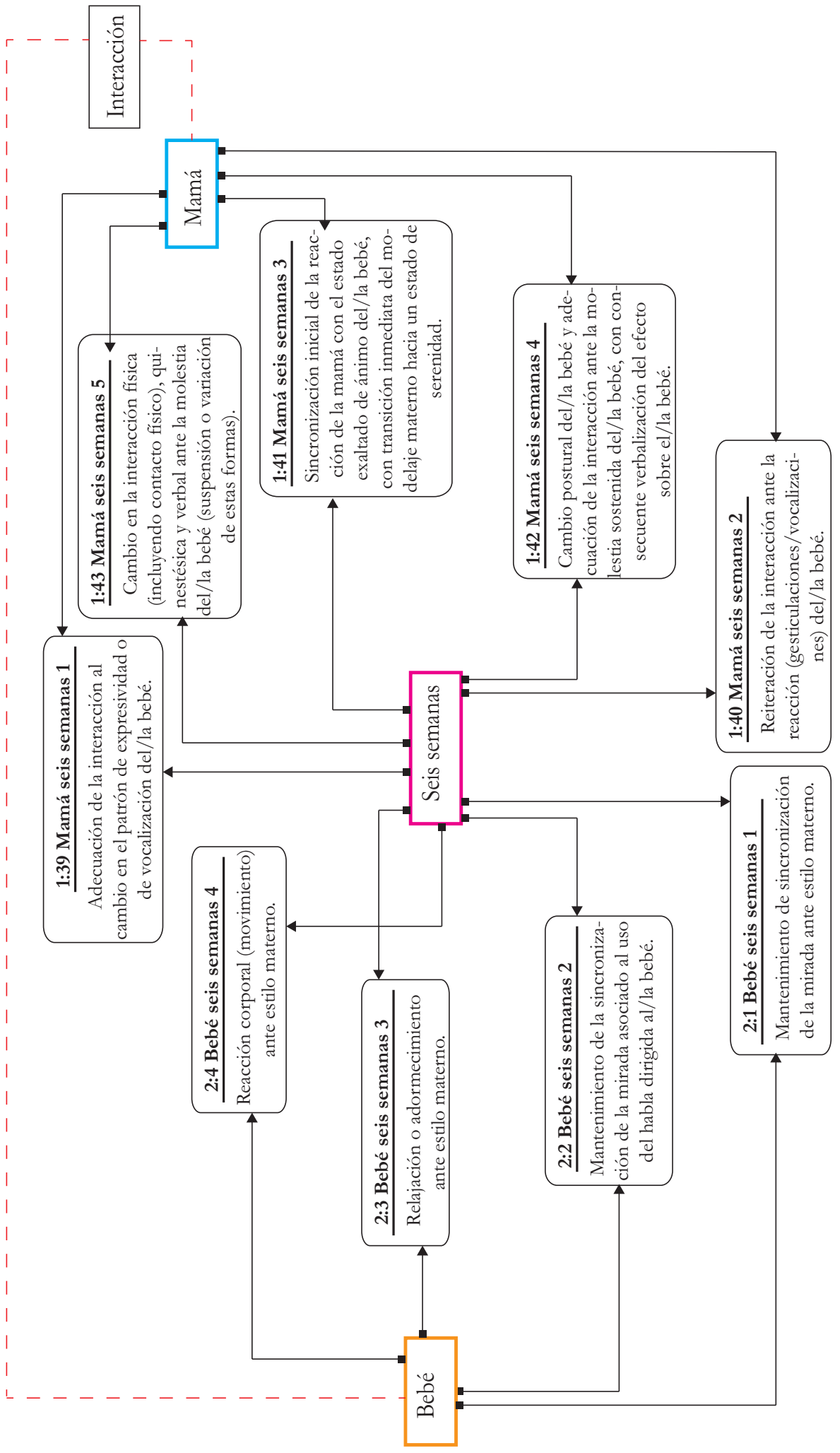

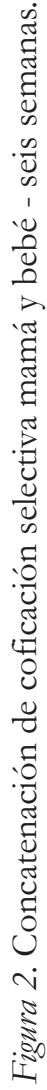

Actualidades en Psicología, 34(128), 2020, 69-101 
de interacciones. Las mamás dimensionaron al/la bebé desde su capacidad intrínseca para percibir con sus sentidos y procesar información. Articularon esta capacidad incipiente que llegaría a fortalecer la propensión de sus bebés a barruntar la intención materna, así como el comportamiento de fenómenos en que participa y que le son presentados. Sus bebés no solo aprehenderían sobre usos, sino sobre cómo está organizado el contexto en función de su manejo, así como de sus propias destrezas. Esta actividad conjunta inauguró la operación cooperativa.

La sincronización favoreció la concordancia y reciprocidad entre acciones mutuas que empezó a expresarse, no verbal, en la espontaneidad de indicios que identificaron la intencionalidad de gestos y expresiones particulares. Este proceder estuvo orientado a actuar en sintonía, recurriendo a estrategias como cambio postural materno o del bebé, contacto físico y localización mutua del foco de atención, que incluso condujeron a reconfigurar la interacción.

La comunidad en la ejecución implicó compartir intencionalidad, que requirió lectura recíproca de focos de interés y atención, expresada en amoldamiento mutuo del comportamiento. Este amoldamiento implicó la comprensión de la naturaleza de la acción, tanto como de la percepción del estado anímico de la contraparte para mayor agudeza en la concordancia. La sensibilidad ante la ubicación de la contraparte en la interacción condujo a la regulación emocional, sobre todo infantil, en la medida en que las mamás ajustaron las coordenadas hacia un estado de equilibrio, así como de avenencia diádica.

Sobresalió el estilo materno dialógico, con intercambio y alternancia, así como una modulación constante, cuyos contornos prosódicos favorecieron la empatía. La motivación a vocalizar y la elucidación de las vocalizaciones o exclamaciones infantiles como partes en un diálogo lo ilustraron.

Las mamás implementaron un estilo que contempló estas dimensiones y visualizó al/la bebé con una subjetividad emergente, proclive a receptividad y reciprocidad. Continuamente dilucidaron y verbalizaron para sus bebés, tanto lo que observaban objetivamente, como lo que inferían y atribuían como ocurriendo subjetivamente en sus bebés, mostrando el camino hacia la construcción del significado de acciones. El primer bosquejo distinguible en esta dirección fue la conformación de un ámbito de interacción.

Los/las bebés recibieron y procesaron la estimulación materna, en una definida disposición incipiente. Mostraron poseer la expresividad para, rudimentaria pero eficazmente, reflejar su efecto.

La consecución, mantenimiento o recuperación del equilibrio (relajación y serenidad) se asoció con que inadecuación o cambio fueron evidenciados y llamados a la rectificación por medio de reacciones de malestar (sollozo y berrinche).

La tendencia a establecer y mantener la sincronización de mirada apareció precoz, aunque fugaz, y se vinculó con la percepción infantil del intento materno por lograrla. La sincronización de mirada coincidía con el habla infantilizada (baby talk) y con el estilo dialógico materno (prosodia), haciendo presumible la atracción inicial hacia este estilo materno, así como sentir molestia y demostrarlo cuando se interrumpía o cambiaba. 
La percepción infantil de configuraciones de estímulos abarcó gestos, sonrisas, movimiento corporal, vocalizaciones y diversas exclamaciones, destacándose la coincidencia de su sonrisa con la materna, que poseyó un componente comunicativo inicial para inducir una acción materna. Las mamás sonreían y vocalizaban simultáneamente y los/las bebés cifraron su atención en este conjunto, sonriendo a su vez. Aunque restringidas sus posibilidades de exclamación o vocalización, sonidos guturales precursores aparecieron asociados a formas expresivas. Así, los/las bebés progresaron hacia consolidar FI, incluyendo movimientos corporales asociados a malestar o serenidad, y la vocalización.

Los/las bebés orientaron su mirada y giraron su cabeza hacia los estímulos y así transmitían a las mamás claves sobre el foco de su atención que se encauzó hacia la coincidencia inherente. Este ámbito emergente parecía concentrarse en rasgos sobresalientes de la interacción, para filtrar y aislar la influencia de estímulos no inmediatamente relevantes.

La transición entre estados de ánimo, de serenidad a malestar, pautó la interacción y anticipó estrategias para la acción, sobre todo materna. La transición estableció una sucesión, una alternancia o recuperación de un determinado estado en la vinculación.

La tendencia hacia la concordancia instauró el deliberado y constante esfuerzo materno por empatar con necesidades infantiles y el imperativo por obtener insumos requeridos para el equilibrio en la interacción, e inclinó la acción diádica hacia la regulación emocional.

Seis meses: codificación selectiva de mamá y bebé

Con objetos se denominaron acciones, se propusieron juegos, se designaron cosas, se cualificaron objetos, los rasgos del comportamiento fueron nombrados, se evocaron situaciones. Se introdujo una triangulación fluida en aras del desarrollo de capacidad meta representacional (Fajardo-Santamaría, 2018).

Así, acciones infantiles se tornaron evidentes para las mamás quienes las perfilaron a su vez. Les dieron un lugar en el diálogo, las enunciaron en la interacción (ver Figura 3).

No solo el entorno delineó sus contornos, también la singularidad infantil predominó en la definición de los sucesos. Su protagonismo se reafirmó en opciones lúdicas abiertas por objetos.

El protagonismo para los/las bebés constituyó una posibilidad para introducir nuevas fases en el proceso. La propuesta materna parecía guiarse progresivamente por lo que suponía era la iniciativa infantil. En el plano del significado que la acción adquirió para las mamás, la distinción de la singularidad infantil fue derrotero.

Los objetos fueron mediadores versátiles de acciones y sus variantes. Conectaron intereses diádicos. Fueron vehículos de sensaciones y canales para la expresividad. Los objetos introdujeron palabras y condujeron el estilo materno;fueron vehículo para establecer contacto. Las mamás escudriñaron la atención de sus bebés, detectaron las claves de la interacción.

Los objetos abrieron posibilidades para representar e introducir diversificaciones y variaciones en la acción circulante, que se asociaron con percepciones, en intentos por traducir la acción en un sensación distinguible y registrable para los/las bebés. 


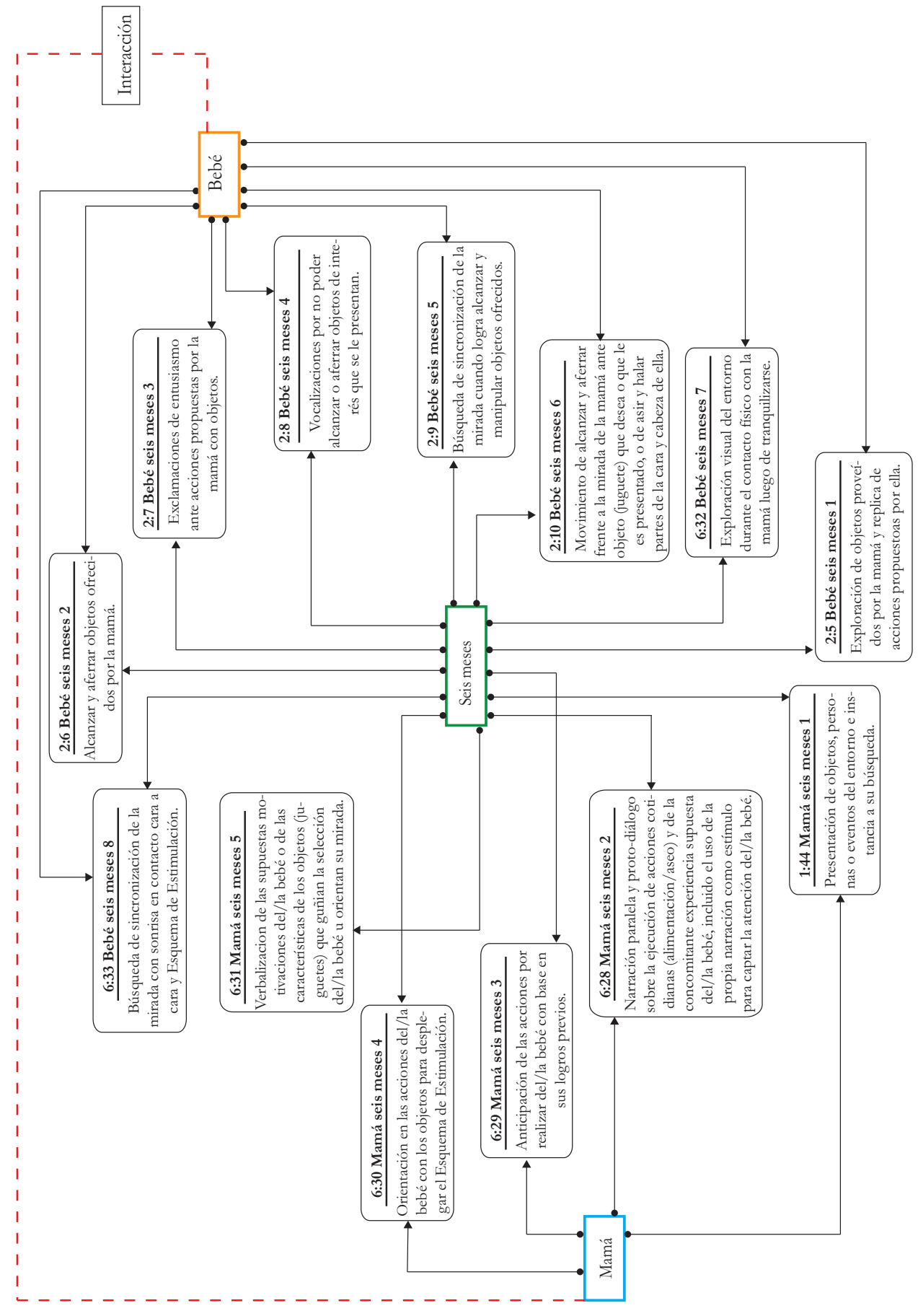

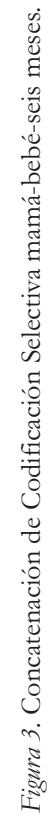


La propuesta materna ensambló indicios para reconocer eventos más allá de la actividad diádica inmediata. Fue una forma preliminar de apertura a novedades del entorno. La diversificación y la apertura, con énfasis en las percepciones infantiles, se fundieron en el interés por actividades que emergían desde motivaciones infantiles.

Las mamás se basaron en pistas que recibían e identificaban por parte de sus bebés. Se afinó su ajuste a la supuesta intencionalidad infantil, sus motivaciones, el interés por objetos o eventos, al foco de su atención, al sentido de sus movimientos corporales (incluyendo la direccionalidad de su mirada), a su presumido interés por la funcionalidad de objetos y sus propias habilidades, y a su apremio por realizar determinadas acciones. Este refinamiento en la percepción nutrió la sensibilidad hacia estados de ánimo y cambios humorales subyacentes a la regulación emocional.

Por tener implícita la introducción a actividades y prácticas con carácter social, la escenificación de acciones con objetos explicitó el involucramiento en el mundo social. Las mamás evocaron situaciones vividas conjuntamente o las convocaron desde ámbitos sociales para personificarlas frente al/la bebé con objetos, e ilustrar no solo pautas que rigen el comportamiento social, sino también emociones y pensamientos asociados. La actividad conllevó la representación de patrones y modelos sociales que demandaron un nivel lingüístico y semántico superior, con un importante componente de comunicación no verbal. La representación invitaba a reproducir escenas, lo cual exigió imaginación y fantasía para recuperar y recrear la experiencia. En este plano, las mamás invitaron al/la bebé a integrar, identificar y asumir roles sociales, a moverse hacia la representación. La constante labor de elucidación y verbalización materna de acontecimientos adquirió el carácter de un renovado desafío a la función simbólica.

Los/las bebés desplegaron secuencias de acciones de mínima complejidad, al ejercitar funciones por su cuenta o impulsadas por las mamás, incluso como un fin en sí mismo. Estas funciones subyacían a acciones como repetir rutinas elementales, asociadas al manejo corporal o a la manipulación de objetos, con los que ensayaron usos posibles en varias combinaciones; le atrajeron sus atributos, visuales y auditivos, no solo cuando fueron presentados por las mamás, sino durante la exploración propia. Alcanzarlos y aferrarlos mostró cómo conjugar interés con acción. El seguimiento del juego materno con objetos y la incorporación a la actividad, por medio de replicación rudimentaria o mera exploración, destacó que percibían e intentaban reproducir acciones con una intencionalidad.

Los/las bebés desarrollaron acciones en paralelo con las mamás y, simultánea o alternadamente, ejecutaron una propia. Advirtieron cambios introducidos en las propuestas maternas y los asimilaron o juguetearon con ellos, aunque fuera por medio de la atención en la novedad.

Cuando la acción requería cambio postural o ensayo de proezas, como alcanzar y aferrar, o hazañas como estirar brazos y piernas en prono, la incorporación del modelaje materno con objetos o el cuerpo infantil se reflejó en la reproducción motu proprio de estas acciones. Los/las bebés se apropiaron del juego materno con iniciativas propias. No solo percibieron estímulos aislados, como sonoridad, forma o color de los objetos, o movimientos y gestos 
maternos llamativos, sino eventos compuestos. Interconectándose diferentes propiedades, así como formas y estrategias maternas para la acción.

Los/las bebés acompañaron su acción con sincronización de mirada, vocalizaciones variadas, risas y sonrisas, gestos, movimientos corporales (incluyendo alcanzar y aferrar) y exclamaciones de entusiasmo o desgano, con un correlato corporal. Utilizaron estos recursos durante el seguimiento, intento de réplica o innovación de la acción diádica. Este rasgo no se derivó exclusivamente de la adyacencia de acciones diádicas, sino que requirió la compartición para progresar hacia FI versátiles. La concordancia de acción diádica recogió esta dimensión del desafío infantil en la interacción.

Un eje fue que la díada acordara lo que comparte, tanto como dónde y a partir de cuáles insumos. Esta labor de reconocimiento del terreno delineó límites para la interacción, flexibles pero claros. Los/las bebés enunciaron su transgresión cuando protestaban por la retirada materna, por la interrupción o por la inserción inoportuna. Pugnaron por una ampliación de límites cuando se desplazaban físicamente o mudaban su atención hacia eventos, personas u objetos previamente destacables solo en la periferia del ámbito de interacción. Los/las bebés también volvían a los límites trazados y, eventualmente, agregaron algún elemento proveído por la exploración. Así, pautaron sus propias iniciativas para coordinar la acción materna. Sincronizar la mirada les orientó en la invitación materna, al identificar focos de atención y la probable intencionalidad de la acción, lo cual se imponía antes y después de culminar ciertas acciones individuales o compartidas. Esta sincronización complementó dispositivos expresivos (risas, sonrisas, gestos, exclamaciones o vocalizaciones), como indicio de su logro.

La acción infantil no fue mimesis de la materna, sino diferenciación que empleó habilidades y destrezas, tanto como un caudal para exteriorizar emociones asociadas y el interés por la actividad. Tampoco fue imitación del comportamiento de aspectos aislados de eventos, sino reelaboración - elemental - que contempló facetas del acontecimiento e incluye primeras tentativas de acción autónoma.

Los recursos infantiles exteriorizaron estados de ánimo, al dirigir las capacidades a atender el desenvolvimiento de acciones a las que las mamás invitaban o en las que engancharon autónomamente, pero también asistieron con sonrisas, exclamaciones, gestos y hasta vocalizaciones asociadas al estado emocional. El sollozo indicó falta de interés por estímulos o molestia por suspensión de acciones o retirada materna. Se desencadenaba una protesta en forma de movimientos corporales y vocalizaciones, así como pérdida de interés por acciones que previamente captaron la atención. Recuperar el equilibrio gracias a la intervención materna propicia, al tranquilizar con mimos físicos y verbales, fue señal de que distinguían y se acomodaban a la transición.

Los/las bebés integraron un manejo dúctil y extenso de vocalizaciones básicas efectivas, como respuesta a la invitación materna y para captar atención. Reportaron que el estímulo se iba en la dirección apropiada. La vocalización indujo a proveerles información y se convirtió en medio para requerirla. Dado que las mamás no cesaban de dialogar y verbalizar, incluyendo onomatopeyas, la vocalización infantil ensayó la estructura dialógica y esbozó la comunicación basada en la inscripción en progreso de un rasgo expresivo dentro de un derrotero simbólico. 


\section{Un año: codificación selectiva de mamá y bebé}

La Figura 4 muestra la composición escénica (enactments, Morgenroth, 2010) que dio inicio a la inducción semiótica por medio de la transmisión de planes culturales (Trevarthen, 2015a).

Llamar las cosas por su nombre implicó descomponer la actividad en episodios semánticos. El aparente azar de la interacción evidenció orden al desarticularse en fragmentos con sentido. La división en intencionalidades, sensaciones, intenciones y metas construyó un campo semántico común.

Las mamás organizaron paulatinamente indicios sobre el propósito de acciones, en unidades de mayor complejidad, en escenas reconocibles, al seguir el orden cotidiano, preparando cada movimiento común para su instauración en el continuo social. Con cada denotación, las mamás despertaron interés por su enlace con comportamientos habituales.

Unidades de sentido más complejas constituyeron escenas discernibles, por medio de signos en el orden cotidiano. Guiones breves de acontecimientos frecuentes y en series cortas para la comprensión secuencial del sentido de la acción para los/las bebés. Desde pequeños gestos convencionales, como saludos, hasta instrucciones de relativa complejidad, como intercambios; pasando por bailes y cantos, ejemplificaron un mundo social compuesto por un sí mismo y una contraparte, con variaciones.

En las escenas, los objetos ganaron contornos y cualidades, dotados de atributos atractivos, y se insertaron en el devenir de las ideas a compartir para dinamizar la interacción.

Las mamás transformaron los guiones de escenas en breves relatos que subrayaban el carácter social de mímica y mimetismo.

Los relatos incluyeron escenas para la comprensión del mundo social que se derivaron del juego corporal y de su potencial para descubrir nuevas posibilidades. El ensayo lúdico se elevó al estatus de contenido para la cognición social.

Las mamás dramatizaron guiones que mostraban propósitos en la interacción y que se desenvolvían en el orden de un contexto particular, incentivaban la iniciativa o el involucramiento infantil en la secuenciación de acciones y así la socialización proporcionó modelos. La inducción semántica no solo enunció cada acción y un potencial significado en un entramado lingüístico, sino su inscripción constante en el mundo social. El estilo materno llevó al/la bebé hacia la comprensión escénica del entorno mediato desde la interacción inmediata.

Las mamás precisaron constantemente el reconocimiento de focos de interés y atención, así como la caracterización más elaborada de acciones implicadas, ahora más complejas y secuenciales; diversificaron su propio empleo de la sincronización y del seguimiento de la mirada, así como del señalamiento, en su propuesta de acciones y para referirse a las infantiles.

Las mamás aludían, en sus apreciaciones constantes, a secuencias y conjuntos de acciones de sus bebés que se regían por la ejecución con objetos y mediada por objetos o que se articulaban alrededor del cuerpo infantil, debido al dinamismo de sus acciones. La recolocación postural diádica, por iniciativa materna o infantil, incluyó búsqueda del contacto cara a cara, al servicio de la constante adaptación dúctil del ángulo más conveniente de la acción. 


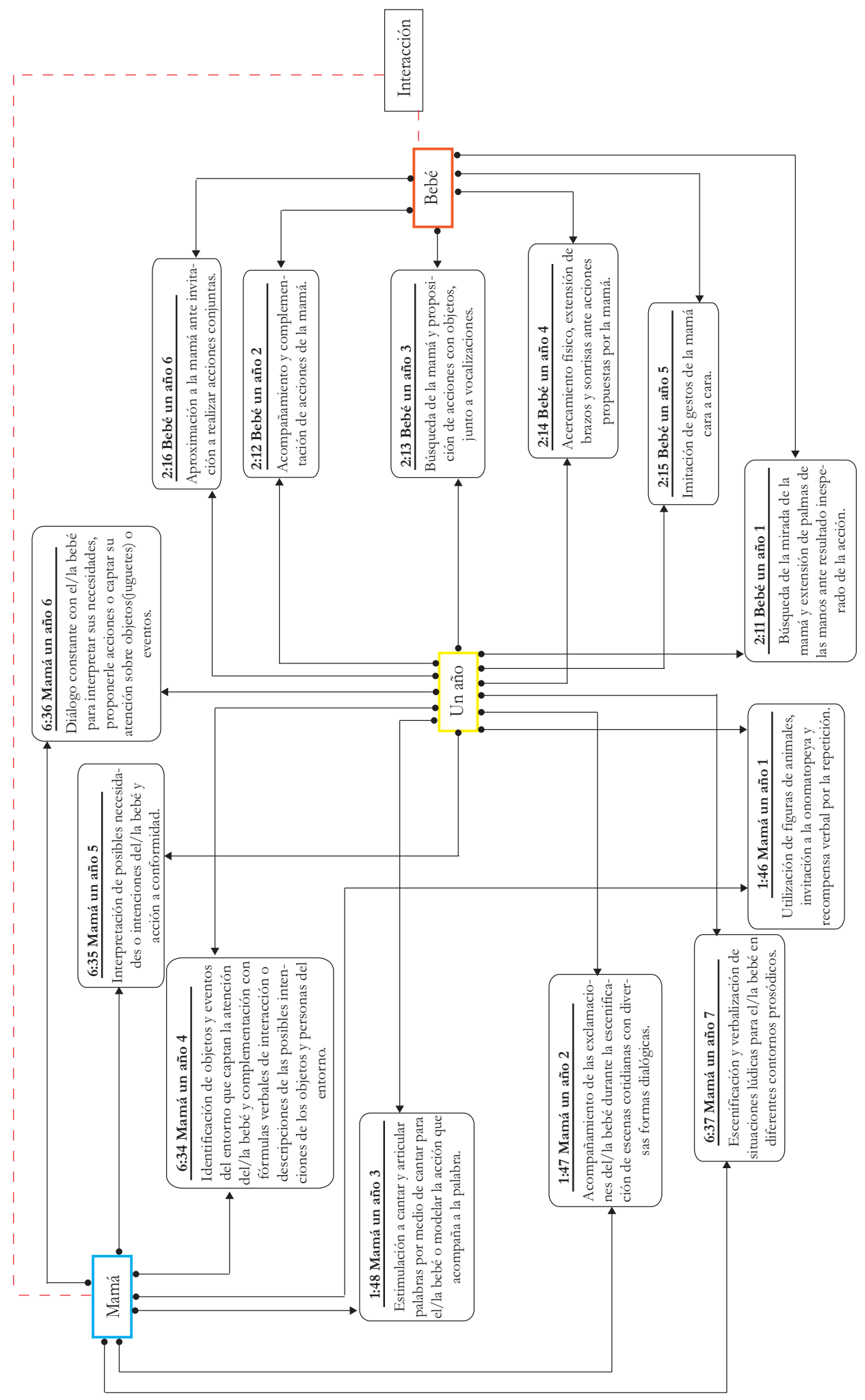

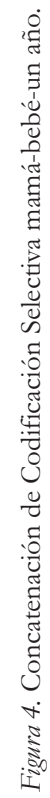

Actualidades en Psicología, 34(128), 2020, 69-101 
Las mamás derivaron sus intervenciones e invitaciones, con mayor énfasis, de acciones infantiles, gracias al intercambio de gestos y exclamaciones, acompañados de vocalizaciones que las mamás promovían y ofrecían como modelaje.

Las mamás matizaron sus vocalizaciones y verbalizaciones con declinaciones prosódicas para acentuar el contenido emocional que sobresalía en la interacción como relevante para sus bebés. Este juego de la posibilidad creciente de realizar acciones compartidas, recurrió a la sincronización de mirada y mutua retroalimentación, con indicadores sensoriales y semánticos transitando en ambas direcciones, cuyo significado fue introducido en la interacción.

La invitación materna a manifestarse por medio de gestos y exclamaciones, en una amplia gama, no fue solo un ejercicio indispensable sobre la estructura dialógica, sino una acción con significado por sí misma; encauzada a la transmisión en ambas direcciones de un mensaje con sentido definido, como parte de inaugurar gradualmente la praxis del habla. La verbalización de acciones observadas por las mamás se aunó con la narración de historias o eventos que deducían el atractivo para sus bebés.

La escenificación de acciones con objetos se amplificó con dramatización de emociones diversas, fuera como estados de ánimo atribuibles al/la bebé o como parte de situaciones de carácter social.

La tarea materna se complejizó pues ahora los/las bebés también protagonizaban con objetos escenas, aunque fuesen esbozos primigenios, conquistando la capacidad para ejecutar lúdicamente por su cuenta y con cierta fidelidad, situaciones cotidianas (como acercar una silla a la puerta y encaramarse para abrirla).

La elucidación materna al/la bebé sobre las acciones en proceso, las que le propone o las que deduce que intenta, así como las instrucciones asociadas que le imparte verbal o analógicamente, enlazaron la inducción lingüística y la semántica. Cada interés atribuido al/ la bebé, las mamás lo tradujeron en acción, en nuevo desafío comprehensivo, achicando un espacio semántico tras otro. Cada exclamación o vocalización infantil, incluso el balbuceo, sería recibida y descifrada como intento por expresar contenido particular que se procuró traducir en palabras o acompañar con formas dialógicas.

Esta traducción utilizó la pregunta al/la bebé sobre la naturaleza de sus acciones o sus intereses, así como sobre la secuencia a seguir, con lo cual la inducción lingüística y la semántica ofrecieron un complemento sobre usos polisémicos de objetos. Las mamás tampoco se cansaron de describir y nombrar objetos o su utilidad. La sugestión materna sobre lo que es posible se orientó a activar capacidades perceptivas y funcionales de sus bebés, con juegos corporales. Tampoco se interrumpían las tentativas de explicitar la perspectiva interna infantil sobre los acontecimientos y la probable experiencia subjetiva en los contextos contenedores, enfatizando la creciente comprensión infantil de la dinámica intrínseca.

Potenciar la capacidad expresiva fue núcleo estratégico. Compartir planes para la acción y la coincidencia de intereses fue una prioridad, por contribuir a consolidar habilidades y destrezas infantiles en desarrollo, que afianzaron un matiz social. El enriquecimiento de expresividad fue crucial. La función del intercambio de risas y sonrisas señaló la consecución 
de reciprocidad y cooperación de acciones, en las que confluyeron componentes emocionales, la comprensión del significado del evento y la capacidad expresiva.

Para las mamás, fortalecer la expresividad recabó indicadores sobre cualidades de la experiencia por la que atravesaron sus bebés, coligiendo estrategias para la acción o ajustes necesarios para sintonizar y, eventualmente, transferir insumos para la estabilización recíproca.

Las mamás no solo siguieron la guía infantil, sino que propiciaron coautoría en los acontecimientos al promover la capacidad infantil para visualizarse, con sus destrezas y habilidades, en el entramado de las FI.

Reciprocidad y alternancia favorecieron el desplazamiento físico de los/las bebés y sus recorridos perceptuales por focos de interés para integrar acciones de mayor complejidad, definiendo participaciones propias y maternas en guiones que mostraron tanto la transmisión (infantil) como la recepción (materna) de una intencionalidad hacia metas.

Los/las bebés entremezclaron vocalizaciones en distintos momentos y formas durante la coordinación y ejecución de actividades compartidas. La expresividad sonora de la voz participó del juego de intercambio diádico como elemento decisivo al organizar y conducir acciones.

El intercambio diádico condujo al/la bebé hacia una participación estructurada alrededor de nominalizar la acción, entendida como conjunto de partículas del comportamiento organizándose alrededor de un propósito, con epicentro en la mutualidad. La acción reclamó un sentido, expresado en un fin. Esta estructuración fue topicalización que devino acto semántico.

El juego verbal materno y la expresividad vocal infantil, integrada a la estructuración recíproca de eventos diádicos, fueron elementos de una atmósfera ornamentada con una sonoridad cuyas unidades se diferencian para denotar y connotar el sentido emergente de la interacción. Vocalizar no fue un acontecimiento fortuito, sino parte de su esquema comprensivo de la actividad diádica.

La afinación de la inferencia infantil sobre el propósito de la acción y los requerimientos propios y maternos para culminarla subrayó el entendimiento no verbal de la dinámica diádica.

La agudización comprensiva para atender y llevar a cabo directrices verbales reflejó el lenguaje receptivo infantil, instaurándose y operando como guía para la acción.

Los/las bebés declararon su atención y emotividad por acciones compartidas (favorables o desfavorables); la riqueza expresiva les permitió introducir su participación en acciones, recibir con agrado o desagrado la invitación materna (incluido el encuentro o reencuentro), manifestar su motivación (o no) a continuar y celebrar el resultado esperado o inesperado con expresiones convenientes, propiciando el intercambio de señales para establecer el equilibrio emocional que sofistica la comunicación.

Formaron parte del intercambio de información el señalamiento, la búsqueda de andamiaje, el entendimiento no verbal recíproco y el incremento en la capacidad comprensiva del lenguaje (receptivo). Este sistema incluyó recursos expresivos como risas, sonrisas, gestos, movimientos corporales, exclamaciones y vocalizaciones. Captar la atención materna, 
reportarle lo que llamaba su atención, proponerle acciones y aceptar su invitación a compartirlas, o expresar el interés o desinterés, fueron finalidades de la mancomunidad de señales.

La búsqueda de la mamá, su encuentro o reencuentro durante la acción y la celebración concomitante, el ofrecimiento, el requerimiento y el hallazgo de objetos, o el seguimiento activo de focos de interés, se facilitaron y mejoró el involucramiento en acciones. Como la sugerencia de una actividad, su ubicación, aceptación o rechazo, la solicitud de reiterarla, el reporte de coincidencia, la petición u ofrecimiento de colaborar, el mostrar agrado o desagrado y el culminar una acción. Este sistema se derivó de coordinar expresividad y acción, para lo cual sincronizar la mirada fue predecesor indispensable, como facilitador de la mancomunidad.

Un logro al enviar y recibir mensajes discernibles fueron las directrices para la acción. Los/las bebés no solo observaron y recrearon acciones creativamente, sino que siguieron instrucciones maternas, verbales o no verbales, para realizarlas o para abstenerse. Giraban la cabeza y dirigían la mirada cuando se les convocaba, se aproximaban cuando eran convidados o la invitación lo exige, seguían con la mirada los desplazamientos maternos, atendieron señalamientos para identificar, concordar y mantener el foco de atención, reconocieron dónde se concentraba la mirada y focalizaban la propia en la misma dirección, buscaban, encontraban y mostraban objetos reclamados, interpretaron el propósito materno de la acción en progreso y participaron complementándola o recreándola; alternativamente, cumplieron con la tarea que mamá les instó a realizar (acompasar un baile) o se abstuvieron de continuar la iniciativa reprimida por mamá (aunque la retomaran para reír por la nueva amonestación).

La capacidad de reproducir acciones espontáneamente, incluso dramatizaciones lúdicas con objetos que las mamás les representaban o juegos de manipulación funcional de partes de su cuerpo, así como de buscar su ayuda o de protagonizar guiones escénicos cotidianos (hábitos, juegos, etc.), y hasta protestar por acciones convidadas, pero no bienvenidas, evidenció la esencia social no solo del sistema de comunicación, sino de FI. Ofrecer objetos señaló el locus de la acción como solicitud de reiteración; la imitación de gestos cara a cara o el juego diádico de intercambio de vocalizaciones destacaron la reproducción de guiones y pautas para la acción social.

Los/las bebés emplazaron a la mamá a participar de sus iniciativas o a reconducir las prioridades maternas en función de las propias. Como complemento y en anticipación al estilo materno, indujeron y condujeron la atención materna. Sus habilidades y destrezas se convirtieron en alertas sobre la conveniencia. En el señalamiento, la sincronización y el seguimiento de la mirada, junto a la solicitud de apoyo, en acciones mediadas por objetos, al requerirlos la mamá o aceptar los ofrecidos por ella, estuvo presente su prioridad. Que la mamá descifrara la intención infantil de cambiar de postura o su necesidad de aproximarse o establecer contacto físico, fue indicio de su capacidad naciente de transmitir esta finalidad y el propósito asociado.

Los/las bebés proporcionaron indicadores del agrado o desagrado con exclamaciones, gestos y vocalizaciones, por el reencuentro con objetos que la mamá escondía para 
sorprenderles o que salieron temporalmente de su percepción, pero que disfrutaron. También celebraron la coincidencia materna con sus intereses, incluido repetir una interacción particular, o protestan por agotamiento, así como para rechazar la iniciativa materna o porque se restringen sus desplazamientos. Mostraron también su interés por expandir el ámbito de interacción hacia objetos o personas que desde la periferia atraían su atención o que salieron momentáneamente de su percepción.

El señalamiento reciproco instauró un receptáculo para la acción común, que favoreció el apoyo materno en la ejecución de acciones, que no solamente logró interacciones integradas alrededor del progreso en la coordinación visomotora y en la capacidad cognitiva, sino también un avance en actividades de connotación social. La solicitud de apoyo derivada del entendimiento y aceptación del ofrecimiento de apoyo materno condujo a acciones conjuntas. La solicitud era tan básica como requerir cambiar de postura, mientras que el ofrecimiento materno, tanto como acercar objetos para alcanzar y aferrar. Lo que incluyó la proposición o reiteración de acciones infantiles por medio de una gama de expresiones corporales, como aproximación y extensión de brazos o manos, expresividades, como risas y gestos, y vocalizaciones múltiples, y para compartir el entusiasmo o la molestia por el resultado.

Compartir el logro instauró un campo semántico con un papel en la asignación de un significado a la acción y estableció un hito en el advenimiento del lenguaje. Este valor semántico destacó en la reproducción infantil de dramatizaciones lúdicas de la mamá con objetos, incluso después de un intervalo de tiempo, junto a gestos, vocalizaciones y risas. Este motu proprio de guiones escénicos evidenció que discernían la transcendencia social de las acciones y esbozó e interiorizó su significado en FI. Esta significación de acciones diádicas remitió a su matiz social.

\section{La secuencia longitudinal durante un año: Codificación Selectiva}

Al año se está en el preludio del lenguaje; recurriendo al supuesto de un patrón de progresión geométrica del desarrollo, basado en cualidades diádicas emergentes de forma diacrónica. Los principales hallazgos pueden representarse teóricamente así:

La Figura 5 muestra cómo los recursos diádicos estuvieron en germen desde temprano en el desarrollo y avanzaron de manera exponencial durante el año, catapultando al sujeto hacia la autonomía.

Con la reciprocidad y alternancia de acciones, la díada pactó el origen y destino de acciones conjuntas, lo cual exigió reconocer la iniciativa de la contraparte o de transmitir con claridad la propia iniciativa. De este arreglo, los/las bebés coligieron cómo de la acción de una parte se desprende la acción afín concomitante. No solo esperaban que la mamá diera su aporte, sino que derivaban que ella pretendía lo mismo y así cuál era la contribución esperada de su parte. Esta habilidad les permitió deducir que la acción materna fuera en sí misma una invitación a participar, lo que trajo consigo que pudieran sentir atracción por instrucciones y por ponerlas en práctica, como cuando entregaban objetos solicitados o dirigían la mirada hacia donde se encontraban. Los/las bebés señalizaron su interés por la invitación con aproximación física y seguimiento con la mirada. Llegaron al involucramiento y mantenimiento en la acción propuesta, añadieron risas, sonrisas, gestos, 


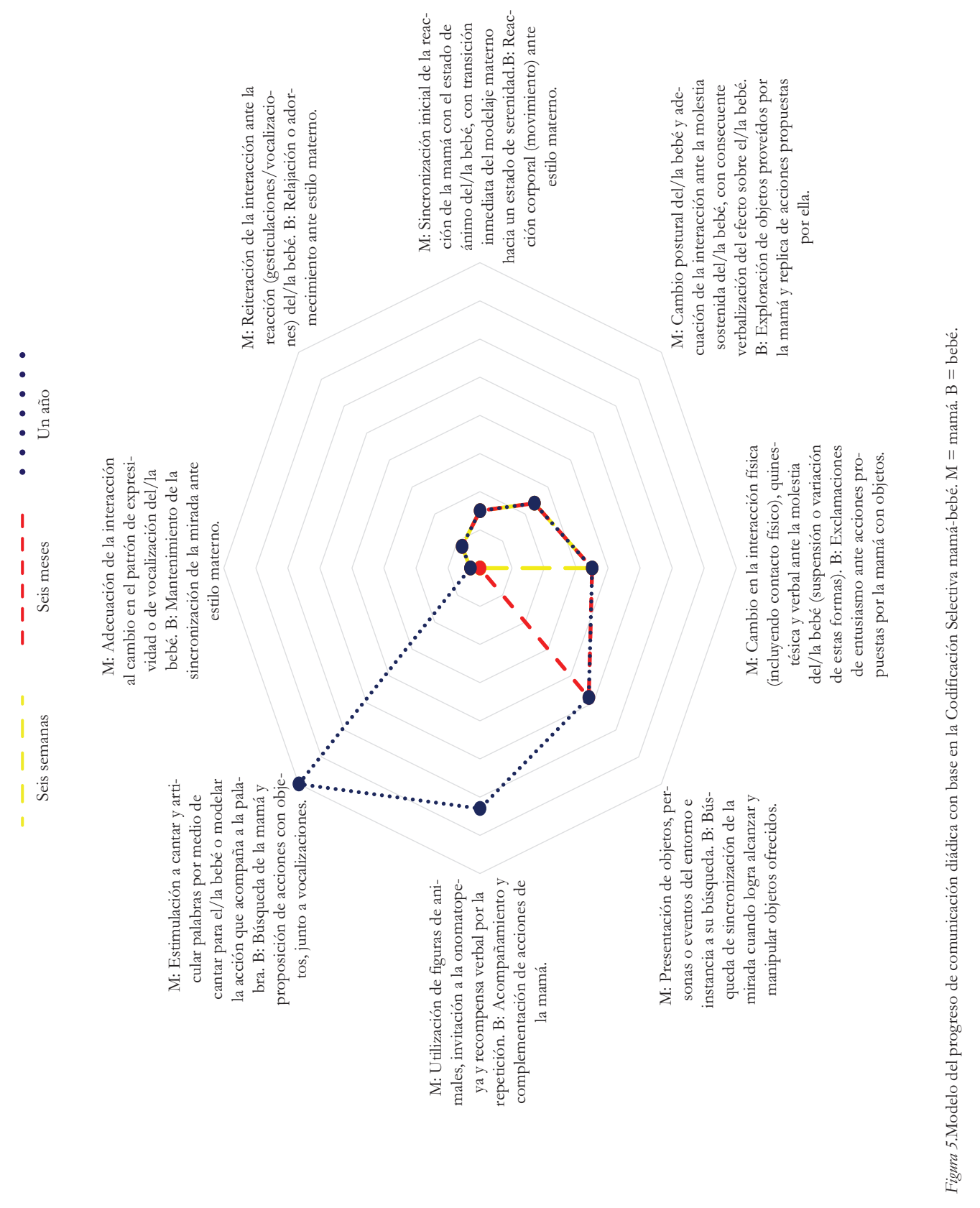


movimientos corporales, vocalizaciones y direccionalidad de la mirada para acentuar el efecto; como extender brazos y manos para reportar su interés por características visuales y sonoras de objetos utilizados por la mamá. Con la reproducción de acciones maternas o la imitación de gestos, onomatopeyas y palabras con vocalizaciones, mostraron su entendimiento del principio de reciprocidad.

El giro de cabeza y la mirada ante la llamada materna, la inhibición eventual de una acción por su reprimenda y el retorno al ámbito de interacción (luego de un desplazamiento), como consecuencia del estilo materno para recuperar su interés; indicaron que deducían cómo comportarse en correspondencia, incluso cuando la respuesta esperada por ella no era de su agrado.

Así como reconocieron una invitación, los/las bebés pudieron cursarla. La sincronización de mirada y el señalamiento inauguró este cometido, reforzado con el ofrecimiento de los/ las bebés de objetos, junto a una propuesta de uso, o con la alerta sobre objetos o eventos del entorno; aunque solo señalaran el lugar de la acción para repetirla. La búsqueda de apoyo materno implicó la expectativa de una respuesta oportuna. Recurrieron a exclamaciones emotivas y vocalizaciones para reportar la coincidencia con su iniciativa.

Cualquier forma de protesta infantil remitió a falta de reciprocidad materna a su expectativa. La búsqueda espontánea de sincronizar la mirada y la extensión de las palmas de las manos ante un resultado inesperado de la acción, indicó que confiaban en que ella compartiría su interés. La alternancia de la mirada infantil entre la mirada materna y el locus de la acción mostró su intento de corroborar la perspectiva en cualquiera de estas opciones.

El juego materno de aparecer y desaparecer objetos, u ofrecerlos y retirarlos, celebrado con risas infantiles, ilustró que los/las bebés no solo se regían por la reciprocidad; sino que captaban el sentido lúdico del camelo materno.

Para culminarla y asentarla, los/las bebés acordaban con la mamá el intercambio de un mensaje claro sobre interés y estado de ánimo asociados a la acción. Cuando sintonizaban, los recursos expresivos transmitieron un mensaje coherente entre ambas partes, como en la reciprocidad del saludo de rencuentro con la mamá con gestos y vocalizaciones y con la reacción infantil ante la música con movimientos de baile. Cuando no, el mensaje infantil denunció la disonancia. En ambos casos, se presentó reciprocidad y concordancia durante el intercambio del mensaje sobre el significado subjetivo de la acción y su carácter social. Sonrisas o sollozo fueron clases dicotómicas a las que recurrieron los/las bebés para expresarse, como agrado o desagrado por la acción propuesta. De aquí se derivaron formas de exteriorizar mutua motivación o discordancia, convertidas en aproximación y entusiasmo o protestas y distanciamiento.

La compartición del campo semántico conllevó establecer alternancia en la acción. Aunque una derivación esperable y fluida de la reciprocidad, la alternancia fue indispensable para que las acciones maternas e infantiles no se traslaparan e interfieran, más allá de cierta frecuencia. Un grado de interferencia se presentó desde las seis semanas, prevaleció a los seis meses y se mantuvo al año, de forma que algunas pistas cruciales que se ofrecieron mutuamente mamá y bebé pudieron amortiguarse. Así emergió el impulso a enviar una señal a la contraparte para pautar el ritmo de las intervenciones. Los/las bebés erigieron como parte del intercambio 
de señales una declaración de inicio de la acción, la cual pudo ser el interés por la invitación materna. Cuando finalizaban una acción, o cuando perdían el interés, recondujeron la mirada, recolocaron la postura corporal, expresaron su molestia, mudaron el foco de atención o se desplazaron, rompiendo los límites del ámbito de interacción.

Recursos expresivos y atencionales contribuyeron a indicar la secuencia pretendida por los/las bebés para las acciones, su intencionalidad y la participación materna requerida. El solo detenerse para observar y percibir el insumo materno ofrecido, fue una pauta de alternancia que facilitó el procesamiento de la información en ingreso.

Los/las bebés se aproximaban a la mamá para proponer acciones y esperan la respuesta materna afín o no, pero raramente se interrumpían en medio de una acción y habitualmente no empezaban otra antes de haber culminado la anterior. Cuando recibían la invitación materna o intentaban hacerla partícipe de la acción, generalmente esperaban a que mamá diera el paso siguiente en la secuencia. Se alternaron aporte materno e infantil, en la reciprocidad del saludo de rencuentro con gestos y vocalizaciones, en el juego de intercambio de vocalizaciones y de exclamaciones o gestos asociados a acciones. Cuando aferraban y lanzaban lejos de sí objetos ofrecidos por la mamá, quedaban expectantes de la reacción materna subsiguiente o que se repitiera solo para constatar si volvía a ocurrir lo mismo o no.

Las estructuras se organizaron en un sistema de intercambio de señales para convenir un mensaje, cuyas cualidades cognitivas (entendimiento de la naturaleza e intencionalidad de la acción) y emotivas (interés/desinterés y agrado/desagrado por la acción) se entrelazaron, posible porque bebés y mamás acordaron una acción común. La vocalización jugó un papel dúctil y versátil. Los/las bebés vocalizaban con frecuencia antes, durante y al final de las acciones, junto al señalamiento propio o materno, al lado de la solicitud de apoyo materno o la oferta proveniente de ella.

La vocalización se apareó con formas de expresividad que fueron desde la postura corporal, movimientos corporales, agitación o extensión de brazos y manos, gestos, risas y sonrisas, aproximación o alejamiento de la mamá y del ámbito de interacción, hasta sollozo., Esto se relacionó con inicio, pérdida o recuperación del interés y la atención sobre objetos, personas o eventos, así como con la iniciativa propia o materna sobre las acciones. La vocalización fue una forma de aceptar la invitación materna o de introducir la propia. La vocalización adquirió formas más funcionales, como en la respuesta a la invitación materna a repetir onomatopeyas, cantar o articular palabras, pero sobre todo en el juego de intercambio de vocalizaciones con la mamá, por iniciativa propia o materna. Estos modos instrumentales adquirieron sentido cuando se coligaron con un sistema de comunicación basado en el carácter social de FI. El contenido de la comunicación fue la experiencia del sujeto en su contexto, la praxis social comprendida en la díada.

Los/las bebés ocasionalmente se involucraron en acciones domésticas, no dirigidas ni necesaria ni intencionalmente por la mamá, de una forma espontánea y alternando la mirada entre el sitio de la acción y la ubicación materna, mientras vocalizaban durante el intento. Esta capacidad para reproducir guiones escénicos, la aplicaron a la intervención espontánea y motu proprio en el mundo social. 


\section{Discusión}

Las limitaciones del estudio se derivan de basarse en el microanálisis de ocho díadas costarricenses, con singularidades sociodemográficas. Sus hallazgos son una guía para posteriores indagaciones sobre metas y estilos de socialización con cometidos conducentes a la subjetivación y al lenguaje, con énfasis en la diada al interior del andamiaje sociocultural. Las mamás no interactúan en todo contexto como se sintetizó la labor de estas participantes, pero es presumible que metas similares e incluso distintas puedan lograrse por caminos diversos a partir de los recursos basales identificados aquí, aunque también es concebible que modelos societales disímiles compartan algunos principios básicos. Más investigación es requerida para contrastar estos hallazgos en distintas composiciones sociodemográficas y étnicas, para lo cual analizar los videos con mamás participantes dilucidaría las metas de socialización y las meta-representaciones de la intencionalidad materna, con un Q-sort derivado de categorías axiales del presente estudio. Así, se afrontaría también la limitación en cuanto a determinar la propiciación de rasgos subjetivos de independencia o interdependencia.

Las fortalezas del estudio incluyen la aproximación a la socialización desde un abordaje basado en validez ecológica (filmación de actividades cotidianas) y en codificación secuencial de interacciones cara a cara, con registros longitudinales tripartitos del primer año de vida infantil que permiten contrastarlos teóricamente. El análisis se apoya, pero también confronta posiciones que remiten al apego como estructura ontológica por antonomasia de la fundación de la subjetividad y a la sensibilidad materna como la habilidad de identificar claves infantiles para ponderar la priorización de necesidades del desarrollo y ofrecer una respuesta oportuna, pero que la reducen a una dimensión en gradiente a contrastar transculturalmente (Woldarsky et al., 2019).

Los hallazgos destacan el campo semiótico (Trevarthen, 2015a) - escénico, construido dualmente y que incorpora la mediación cultural, posición derivada de planteamientos de Lorenzer recogidos por Leithäuser (2012). Asimismo, los hallazgos recuperan la definición de Morgenroth (2010) sobre la relación edificándose sobre escenificar guiones culturales, ligados no solo a patrones de crianza, sino a la subjetivación infantil de acuerdo con metas de socialización que presumiblemente priorizan determinados rasgos societales. No se cuestionan cualidades de la maternidad relevantes en el vínculo ni la vinculación en sí como rasgos distintivos que, en definitiva, contribuyen a caracterizar formas específicas de socialización con estilos particulares según el contexto. El planteamiento remite más bien al cómo mamá y bebé se vinculan al ámbito sociocultural. Los hallazgos atestiguan la importancia de la triangulación constante con eventos y personas contextuales, como pivote para orientar al sujeto infantil en su mundo social de referencia. La tríada permitiría la perspectiva más conveniente de la acción, la dilucidación recíproca de eventos, la concreción de mensajes con sentido en la significación de acciones mancomunadas, las nominalizaciones de contextos para la acción como partes complementarias de FI, por medio de narrar constantemente el juego interactivo que conviene al advenimiento del lenguaje. Esta estrategia basal objetiva al sujeto en sus acciones. La interacción con secuencias y combinaciones de intereses infantiles remite a distintos planos del comportamiento infantil, tanto como lo logra la manipulación de objetos y la integración 
de estímulos sensoriales y propioceptivos para discernir sobre eventos multifacéticos. La estrategia conducirá al ámbito de interacción como dinamismo interactivo, por medio de acciones compartidas, moduladas por el intercambio de señales, el registro de emociones predominantes y la intencionalidad de la acción. El resultado: un campo semiótico - escénico para el advenimiento del lenguaje. Hasta donde este estudio indagó, existe escasa investigación sobre procesos de vinculación diádica en enlace con la transmisión de contenidos socioculturales por medio de estrategias de crianza, que enfaticen los precursores del habla (protosign y protospeech, Arbib, Gasser, \& Barrés, 2014) como claves de regulación emocional (DiCorcia et al., 2016) que facultan progresivamente al sujeto a construir cogniciones incipientes (De Houwer \& Hermans, 2010) sobre su entorno y el dinamismo circundante. Se requiere mayor investigación sobre orígenes y dinámicas de las estrategias maternales en la díada y su articulación con el contexto, sobre todo en relación a cuáles acontecimientos resultan esenciales para capturar la atención infantil o para extraer de intereses y logros infantiles claves para guiar metas de socialización, así como sobre la concordancia de ambas dimensiones y, eventualmente, si guardan alguna conexión con orientar la subjetivación hacia individualidad o colectividad, como formas de "unicidad preverbal de la significación humana" (Trevarthen, 2015a, 2015b), en el andamiaje (scaffolding) lúdico (Marjanovič-Umek \& Fekonja-Peklaj, 2017), entre microsistema (díada) y mesosistema (prácticas culturales subyacentes a estilos de crianza), según formulan Edwards y Liu (2002) o Thomson (2006).

\section{Referencias}

Andrés-Viloria, C., \& Fernández-González, A. (2016). Las prácticas de crianza de los padres: su influencia en las nuevas problemáticas en la primera infancia. Revista nacional e internacional de educación inclusiva, 9(1), 30-42.

Arbib, M., Gasser, B., \& Barrès, V. (2014). Language is handy but is it embodied? Neuropsychologia, 55, 57-70. doi:10.1016/j.neuropsychologia.2013.11.004

Baquero, S., \& Segovia, A. (2018). Cognición corporizada y comprensión semántica. Pensamiento Psicológico, 16 (2). doi:10.11144/Javerianacali.PPSI16-2.cccs

Barbosa, M., Beeghly, M., Moreira, J., Tronick, E., \& Fuertes, M. (2018). Robust Stability and Physiological Correlates of Infants' Patterns of Regulatory Behavior in the Still-Face Paradigm at 3 and 9 Months. Developmental Psychology, 54 (11), 2032-2042. doi:10.1037/dev0000616

Beebe, B. (2017). Daniel Stern: microanalysis and the empirical infant research foundations. Psychoanalytic Inquiry, 37 (4), 228-241. doi:10.1080/07351690.2017.1299498

Bermúdez-Jaimes, M. E., \& Escobar, H. A. (2014). Comprensión social y lenguaje: ¿dos dominios?. Universitas Psychologica, 13(1), 345-356. doi:10.11144/Javeriana.UPSY13-1.

Bordoni, M. (2018). El entonamiento afectivo en las interacciones tempranas adulto bebé: una revisión. Revista Colombiana de Psicología, 27, 13-25. doi:10.15446/rcp.v27n1.61019

Bull, P. (2002). Communication under the microscope. The theory and practice of microanalysis. New York, NY: Routledge. 
Calderón, E. (2017). El papel de la dimensión afectiva en la adquisición del lenguaje materno. Alteridades, 27 (53), 11-22.

Charmaz, K. (2014). Constructing grounded theory. London, England: Sage.

Coudé, G., Festante, F., Cilia, A., Loiacono, V., Bimbi, M., Fogassi, L., \& Ferrari, P. (2016). Mirror neurons of ventral premotor cortex are modulated by social cues provided by others' gaze. The Journal of Neuroscience, 36 (11), 3145-3156. doi:10.1523/ JNEUROSCI.3220-15.2016

De Barbaro, K., Chiba, A., \& Deák, G. (2011). Micro-analysis of infant looking in a naturalistic setting: insights from biologically based models of attention. Developmental Science, 14 (5), 1150-1160. doi:10.1111/j.1467-7687.2011.01066.x

De Houwer, J., \& Hermans, D. (2010). Cognition and Emotion. Reviews of Current Research and Theories. New York: Psychology Press.

DiCorcia, J., Snidman, N., Sravish, A. V., \& Tronick, E. (2016). Evaluating the Nature of the Still-Face Effect in the Double Face-to-Face Still-Face Paradigm Using Different Comparison Groups. Infancy, 21 (3), 332-352. doi:10.1111/ infa. 12123

Edwards, C.P., \& Liu, W-L. (2002). Parenting Toddlers. En M.H. Bornstein (Ed.), Handbook of Parenting, Volume 1, Children and Parenting (pp.45-70).New Jersey - London: Lawrence Erlbaum Associates

Fajardo-Santamaría, J. A. (2018). La interacción social en la ontogénesis de la perspectiva del mundo. Daimon. Revista Internacional de Filosofía, 75, 87-102. doi:10.6018/daimon/327261

Gardner, H., \& Forrester, M. (2010). Analyzing interactions in childhood. Insights from conversation analysis. UK: John Wiley \& Sons.

Green, S., \& Hogan, D. (2005). Researching children's experience. Approaches and methods. California: Sage.

Johnstone, B., \& Marcellino, W. (2010). Dell Hymes and the Ethnography of Communication. The Sage Handbook of Sociolinguistics. England: Dietrich College of Humanities and Social Sciences.

Karmiloff, K., \& Karmiloff-Smith, A. (2001). Pathways to language: From fetus to adolescent. England: Harvard University Press.

Keller, H. (2018). Parenting and socioemotional development in infancy and early childhood, Developmental Review, 50, 31-4.

Kokkinakia, T., Vasdekis, V.G, Koufakia, Z., \&. Trevarthen, C. (2017). Coordination of Emotions in Mother-Infant Dialogues. Infant and Child Development, 26, 1-25. doi:10.1002/icd.1973

Lang, S., Shoppe-Sullivan, S., Kotila, L., Feng, X., Kamp, C., \& Johnson, S. (2014). Relations between father's and mother's infant engagement patterns in dual- 
earner families and toddler competence. Journal of family issues, 35 (8), 1107-1127. doi:10.1177/0192513X14522243

Leithäuser, T. (2012). Psychoanalysis, socialization and society. the psychoanalytical thought and interpretation of Alfred Lorenzer. Forum: Qualitative Social Research, 13 (3), 17.

Lorenzer, A. (2002). Die Sprache, der Sinn, das Unbewusste. Alemania: Klett-Jotta.

Marjanovič-Umek, L., \& Fekonja-Peklaj, U. (2017). The roles of child gender and parental knowledge of child development in parent-child interactive play. Sex Roles, 77,496509. doi:10.1007/s11199-016-0734-7.

Mcmahon, C., Camberis, A-L., Berry, S., \& Gibson. F. (2016). Maternal mind-mindedness: relations with maternal-fetal attachment and stability in the first two years of life: findings from an australian prospective study. Infant Mental Health Journal, 37(1), 17-28. doi:10.1002/imhj.21548

Ministerio de Vivienda y Asentamientos Humanos (2018). Compendio Estadístico de Vivienda 2018 (MIVAH). https://www.mivah.go.cr/Documentos/estadisticas/ compendio_estadistico/Compendio_Estadistico_2018_Informe.pdf

Morales-González, M., Lázaro-García, E., Solovieva, Y., \& Quintanar-Rojas, L. (2014). Evaluación y corrección neuropsicológica del lenguaje en la infancia. Pensamiento Psicológico, 12 (1), 39-53. doi:10.11144/Javerianacali.PPSI12-1.ecnl

Morgenroth, C. (2010). The research relationship, enactments and 'counter-transference' analysis: On the significance of scenic understanding. Psychoanalysis, Culture \& Society, 15 (3), 267-280. doi:10.1057/pcs.2010.11

Ospina-Ospina, S., \& Gallego-Henao, A. (2014). Lenguaje y socialización en la primera infancia: propuesta didáctica para leer y escribir. Katharsis, 17, 9-27.

Peck, S. D. (2003). Measuring sensitivity moment by moment: a microanalytic look at the transmission of attachment. Attachment \& Human Development, 5 (1), 38-63. doi:10.1080/1461673031000078661

Peña-Ramos, M., Vera-Noriega, J., \& Santiz-López, J. (2018). Niñez y crianza en una zona rural tseltal en Altos de Chiapas. Revista Latinoamericana de Ciencias Sociales, Niñezy Juventud, 16 (1), 149-162.

Pickard, J. A., Townsend, M., Caputi, P., \& Grenyer B. F. S. (2017). Observing the influence of mindfulness and attachment styles through mother and infant interaction: a longitudinal study. Infant Mental Health Journal, 38(3), 343-350. doi: 10.1002/imhj.21645

Puura, K., Leppänen, J., Salmelin, R., Mäntymaa, M., Luoma, I., Latva, R., ... Tamminen, T. (2019). Maternal and infant characteristics connected to shared pleasure in dyadic interaction. Infant Mental Health Journal, 40, 459-478. doi: $10.1002 / 21786$

Riggins, S. (Ed.). (2011). Beyond Goffman: Studies on Communication, Institution, and Social Interaction. The Hague: Gruyter. 
Seville-Troike, M. (2003). The ethnography of communication. An introduction. Londres, England: Blackwell.

Thomson, R. A. (2006). The Development of the Person: Social Understanding, Relationships, Conscience, Self. En N. Eisenber (Ed.), Handbook of Child Psychology, Volume Three: Social, Emotional, and Personality Development (pp.24-98). New Jersey, NJ: John Wiley \& Sons, Inc.

Tomasello, M. (2009). Why we cooperate. Massachusetts: MIT Press.

Trevarthen, C. (2015a). Infant semiosis: The psycho-biology of action and shared experience from birth. Cognitive Development, 36, 130-141. doi:10.1016/j.cogdev.2015.09.008

Trevarthen, C. (2015b). Awareness of Infants: What do they, and we, seek? Psychoanalytic Inquiry, 35, 395-416.

Varela-Londoño, S. P., Chinchilla-Salcedo, T., \& Murad-Gutiérrez, V. (2015). Prácticas de crianza en niños y niñas menores de seis años en Colombia. Revista del Instituto de Estudios en Educación Universidad del Norte, 22, 194-215.

Vargas, N., Morales, M. P., Witto, A., Zamorano, J., Olhaberry, M., \& Farkas, C. (2016). ¿En qué medida la mentalización parental y el nivel socioeconómico predicen el lenguaje infantil? Psicoperspectivas. Individuo y Sociedad, 15 (1), 169-180. doi:10.5027/ PSICOPERSPECTIVAS-VOL15-ISSUE1-FULLTEXT-690

Vergara-Hernández, L. (2017). Prácticas de crianza en la primera infancia en los municipios de Riosucio y Manzanares. Zona próxima - Revista del Instituto de Estudios en Educación Universidad del Norte, 27, 22-33.

Wachs, T. D. (2015). Assessing Bioecological Influences. En M.H. Bornstein \& T. Leventhal (Ed.), Handbook of Child Psychology and Developmental Science, Vol 4 (pp. 811-846). New Jersey, NJ: John Wiley \& Sons, Inc.

Willits, J., Saffran, J., \& Lany, J. (2017). Toddlers can use semantic cues to learn difficult nonadjacent dependencies. PsyArXiv. doi: 10.31234/osf.io/4ca78

Woldarsky, V., Urzú, C., Farkas, C., \& Vallotton, C. D. (2019). Differences in chilean and USA mothers' sensitivity considering child gender and temperament. Journal of Child and Family Studies, 28,1937-1947. doi:10.1016/j.infbeh.2016.07.005 


\section{Anexos}

Tabla 3

Ejemplo de codificación bebé - Mediación por objetos (seis meses)

Exploración de objetos proveídos por la mamá y replica de acciones propuestas por ella

Explora objetos proveídos por mamá, los Busca sincronizar mirada con mamá cuando observa, chupetea, manipula, etc. alcanza y manipula el objeto de su interés

\begin{tabular}{|c|c|}
\hline \multicolumn{2}{|c|}{ Alcanzar y aferrar objetos ofrecidos por mamá } \\
\hline $\begin{array}{l}\text { Agarra y aproxima objetos ofrecidos por } \\
\text { mamá }\end{array}$ & $\begin{array}{l}\text { Presta atención visual constante a objetos } \\
\text { acciones propuestas por mamá }\end{array}$ \\
\hline \multicolumn{2}{|c|}{ Exclamaciones de entusiasmo ante acciones propuestas por mamá con objetos } \\
\hline \multicolumn{2}{|c|}{$\begin{array}{ll}\left.\text { Articula balbuceos (“ } b r r r^{2}\right) \text { cuando mamá } & \text { Emite exclamaciones de entusiasmo cuando } \\
\text { realiza determinadas acciones con objetos } & \text { mamá realiza acciones con objetos que despiertan } \\
\text { (para ilustrar su uso posible) } & \text { su interés }\end{array}$} \\
\hline \multicolumn{2}{|c|}{ Vocalizaciones por no poder alcanzar o aferrar objetos de interés que se le presentan } \\
\hline $\begin{array}{l}\text { Emite exclamaciones cuando no alcanza o } \\
\text { pierde objetos de su interés presentados por } \\
\text { mamá }\end{array}$ & $\begin{array}{l}\text { Emite fuertes exclamaciones acompañando } \\
\text { búsqueda o intento de alcanzar el objeto de su } \\
\text { interés }\end{array}$ \\
\hline \multicolumn{2}{|c|}{ Búsqueda de sincronización de mirada cuando alcanza y manipula objetos ofrecidos } \\
\hline $\begin{array}{l}\text { Busca la sincronización de mirada con mamá } \\
\text { luego de ejecutar acciones que comparte con } \\
\text { ella }\end{array}$ & $\begin{array}{l}\text { Sostiene sincronización de mirada con mamá y le } \\
\text { sonríe cuando culminan acciones compartidas }\end{array}$ \\
\hline \multicolumn{2}{|c|}{$\begin{array}{l}\text { Movimiento de alcanzar y aferrar frente a mirada de mamá ante objeto que desea o que le es } \\
\text { presentado, o de asir y halar partes de cara y cabeza de ella }\end{array}$} \\
\hline \multicolumn{2}{|c|}{$\begin{array}{ll}\text { Explora objetos por } & \text { La presentación de estímulos Durante la interacción cara a } \\
\text { manipulación y chupeteo } & \text { auditivos, quinestésicos, visuales cara, extiende brazos y manos } \\
& \text { y verbales por parte de mamá, e intenta asir y halar partes de } \\
& \text { llaman su atención y despiertan cara y cabeza de mamá } \\
& \text { su interés por manipulación de } \\
& \text { objetos por períodos breves }\end{array}$} \\
\hline
\end{tabular}


Tabla 4

Ejemplo de codificación mamá - Escenificación de acciones con objetos (seis meses)

Presentación de objetos, personas o eventos del entorno e instancia a su búsqueda

Nombra objetos y atributos de Presenta objetos interesantes y Llama la atención sobre objetos que bebé descubre en los nombra

las situaciones lúdicas ("BBolaobjetos o personas del verde!") entorno e insta a buscarlos (“¿Dónde está papá?")

Presentación de objetos, personas o eventos del entorno e instancia a su búsqueda

Nombra partes del Retira o quita a bebé Propone acciones Anticipa y verbaliza la objeto con el que objetos con los que está con objetos y las acción consecuente de interactúan ("iLas jugando y los manipula verbaliza ("Si la metes bebé ante propuesta de orejas (del muñeco)?’)

para captar su atención aqui, la bolita, iqué acción con objetos que y dirigir su mirada, pasa?") acompañando con supone realizará ("iLo gestos y exclamaciones que te gusta hacer con las torres es destruirlas?')

Presentación de objetos, personas o eventos del entorno e instancia a su búsqueda

Describe y verbaliza sensaciones Utiliza prosodia de tono Para proponerle nuevas táctiles de bebé sobre objetos, agudo y de sorpresa para acciones, alza a bebé en (“Se siente diferente la madera introducir nuevos objetos frente suyo y le interroga y el plástico?’). en el ámbito interactivo del sobre las opciones juego, destacando cualidades disponibles ("¿'Traigo la de objetos (color, forma, bola, hacemos ejercicios sonoridad). con la bola grande?”, “¿Qué quieres hacer, traigo la cajita?"). 
Tabla 5

Ejemplo de codificación bebé - Concordancia de la acción diádica (al año)

Búsqueda de mirada de mamá y extensión de palmas de las manos ante resultado inesperado de la acción

Busca mirada de mamá y extiende palmas de Recibe saludo de reencuentro con mamá las manos cuando el resultado de la acción (exclamaciones y brazos abiertos), con brazos realizada no es el esperado abiertos, sonrisas y vocalizaciones

Acompañamiento y complementación de acciones de mamá

Capta el propósito de la acción Busca objetos ocultos tras la Busca objetos sugeridos por sugerida por la mamá y se instrucción de mamá o presta atención a involucra durante períodos eventos destacados por ella. prolongados de tiempo

\begin{tabular}{|c|c|}
\hline \multicolumn{2}{|c|}{ Búsqueda de mamá y proposición de acciones con objetos, junto a vocalizaciones } \\
\hline $\begin{array}{ll}\text { Advierte desplazamientos de } & \text { Busca a mamá para proponerle } \\
\text { mamá, (dentro o fuera de su acciones con objetos y emite } \\
\text { espacio inmediato de juego) y } & \text { exclamaciones como forma de } \\
\text { lo expresa con giros de cabeza, solicitud } \\
\text { siguiéndola o buscándola con } \\
\text { la mirada y con vocalizaciones }\end{array}$ & $\begin{array}{l}\text { Cuando ofrece objeto a } \\
\text { mamá, acompaña el acto con } \\
\text { vocalizaciones }\end{array}$ \\
\hline \multicolumn{2}{|c|}{ Acercamiento físico, extensión de brazos y sonrisas ante acciones propuestas por mamá } \\
\hline \multicolumn{2}{|c|}{$\begin{array}{l}\text { Responde con acercamiento físico, extensión } \\
\begin{array}{l}\text { de brazos (para alcanzar) y sonrisas a las de ella de aproximarse para realizar acciones } \\
\text { acciones propuestas por mamá }\end{array} \\
\text { conjuntas }\end{array}$} \\
\hline \multicolumn{2}{|c|}{ Imitación de gestos de mamá cara a cara } \\
\hline $\begin{array}{l}\text { En la interacción cara a cara, Imita y despliega la acción } \\
\text { tiende a imitar gestos de propuesta por mamá (v.g. } \\
\text { mamá. } \\
\text { bailar) y la acompaña con } \\
\text { sonrisas. }\end{array}$ & $\begin{array}{l}\text { Emite balbuceos } \\
\text { exclamaciones cuando } \\
\text { reproduce algunos guiones } \\
\text { escénicos (v.g. quitar los } \\
\text { anteojos a mamá e intentar } \\
\text { ponérselos). }\end{array}$ \\
\hline \multicolumn{2}{|c|}{ Aproximación a mamá ante invitación a realizar acciones conjuntas. } \\
\hline $\begin{array}{ll}\text { Voltea mirada hacia mamá } & \text { Acompaña y complementa } \\
\text { cuando ella le llama la atención } & \text { la acción realizada por mamá } \\
\text { verbalmente sobre objetos. } & \text { (v.g. sujetar objetos, mover } \\
& \text { objetos con un propósito). }\end{array}$ & $\begin{array}{l}\text { Ofrece a mamá objeto } \\
\text { requerido por ella verbalmente } \\
\text { y por medio de gestos } \\
\text { manuales, dirigiendo la mirada } \\
\text { hacia ella. }\end{array}$ \\
\hline
\end{tabular}


Tabla 6

Ejemplo de codificación mamá - Inducción semántica (al año)

Utilización de figuras de animales, invitación a la onomatopeya y recompensa verbal por repetición

Dramatiza con muñecos y Dramatiza y verbaliza Explota recursos sonoros y verbaliza acciones interactivas supuestos estados de ánimo visuales (formas y colores) de con bebé (v.g. besitos, abrazos) con muñecos (v.g. alegría, objetos para atraer atención regocijo) de bebé dentro del ámbito de interacción establecido por ella, junto a exclamaciones y onomatopeyas como estímulos

Acompañamiento de las exclamaciones de bebé durante la escenificación de escenas cotidianas con diversas formas dialógicas

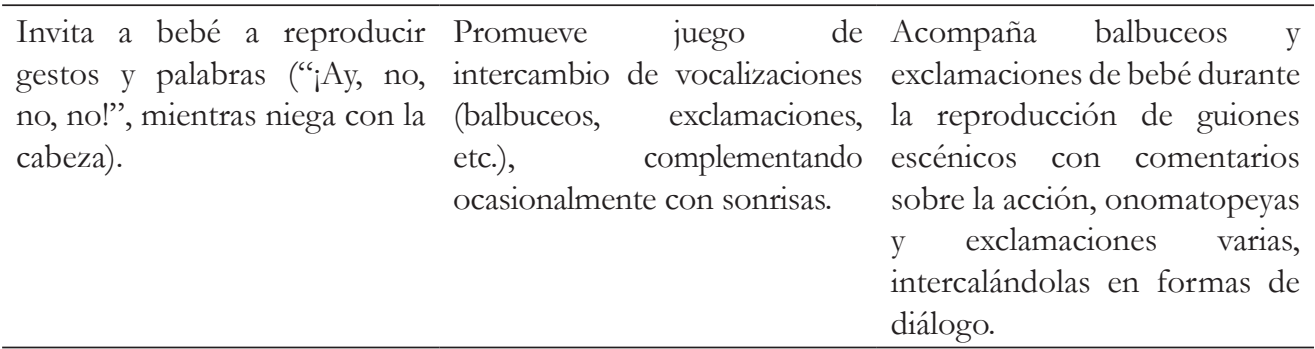

Estimulación a cantar y articular palabras por medio de cantar para bebé o modelar acción que acompaña a palabra

Verbaliza o canta para el/la Estimula a cantar y articular Manipula y modela bebé, en un intento de centrar palabras por medio de cantarle funcionalmente partes del su atención. $\quad$ y modelarle la acción que cuerpo de bebé (v.g. aplausos, acompaña a palabra (v.g. "tortillitas"), mientras canta o articular "hola" y ejecutar el tararea.

gesto de saludo). 